\title{
Fatty Acids in the Lipid of Food Products from Sea Urchin
}

\author{
Masaki Kaneniwa*1 and Toru Takagi*1 \\ (Accepted March 7, 1986)
}

\begin{abstract}
The fatty acid compositions of the lipids from the fermented sea urchin paste, the salted sea urchin gonads, and the raw sea urchin gonads have been investigated with open-tubular gas-liquid chromatography. All the samples contained about $10.1-17.1 \%$ of the unusual 5-olefinic acids such as 5-18:1, 5-20:1, 5, 11-20:2, 5, 13-20:2, 5, 11, 14-20:3, and 5, 11, 14, 17-20:4 and about $0.9-1.3 \%$ of the unusual 7-olefinic acids such as 7,13-22:2 and 7, 15-22:2, similar to the previous studies in our laboratory. The major polyunsaturated acids of these samples were $18: 4 \mathrm{n}-3(0.2-$ $6.3 \%), 20: 4 \mathrm{n}-6(4.1-7.6 \%$, and 20:5n-3 (1.9-17.0\%). All the samples showed about 40 species of fatty acid components and various fatty acid compositions. Especially, the salted sea urchin gonads B contained 20:5 n-3, ten times as much as the salted sea urchin gonads A. It was inferred that the difference between fatty acid compositions of these samples were related to the fatty acid compositions of the sea urchins which were used as the material.
\end{abstract}

The processed sea urchin gonads are fermented marine foods in Japan. The lipids of sea urchins and their food products have been investigated in some previous papers. ${ }^{1-10)}$ Recently, the fatty acid compositions of sea urchin have been elucidated in detail by open-tubular gas-liquid chromatography (GLC) in our laboratory. ${ }^{11-13), * 2}$ The occurrence of the unusual 5-olefinic acids such as 5-18:1, 5-20:1, 5, 11-20:2, 5, 13-20:2, 5, 11, 14-20:3, and 5, 11, 14, 17-20:4 was noticeable in the lipids of sea urchins, amounting to as much as $6-20 \%$ of fatty acids from the total lipids of whole animals. In this study, fatty acids of lipids from two kinds of food products from sea urchin, the fermented sea urchin paste (Neri-uni) and the salted sea urchin gonads (Shio-uni), have been investigated in greater detail. The 5-olefinic acids were found in the lipids of all the samples. The major polyunsaturated acids of these samples were 20:4 n-6 and 20:5 n-3. Recently, these polyunsaturated acids have been noticeable in biochemistry and pharmacology as precursors of prostaglandins. In this study, the contents of the 5-olefinic and polyunsaturated acids of these two kinds of products and the raw sea urchin gonads were compared one another.

\section{Materials and Methods}

\section{Materials}

The samples of the food products from sea urchin studied and the contents of the lipids are listed in Table 1. The fermented sea urchin paste (Neri-uni) and the salted sea urchin gonads (Shiouni) $A$ and $B$ were bought at food markets in Hakodate in February, 1980 (the fermented sea urchin paste and the salted sea urchin gonads A) and October, 1982 (the salted sea urchin gonads B), respectively. The raw gonads were separated from sea urchin Strongylocentrotus nudus obtained from subtidal water near Hakodate. They were kept frozen at $-20^{\circ} \mathrm{C}$ for a few months until used.

\section{Preparation of Methyl Esters}

The total lipids were extracted by the method of Bilgh and Dyer. ${ }^{14}$ Fractionation of the total lipids (TL) into the neutral and polar lipids (NL and PL) was carried out by column chromatography using silicic acid (Kiesel Gel 60, Merck) with chloroform and methanol as the developing solvents. Isolation of triacylglycerols (TG) and free fatty acids (FFA) from NL were carried out by thin-layer chromatography (TLC) with Silica Gel

*1 Faculty of Fisheries, Hokkaido University, Hakodate 041, Japan（金庭正薣，高木 徹：北海道大学水産 学部).

*2 T. Takagi, M. Kaneniwa, and Y. Itabashi: Abstracts of the meeting of Japan. Soc. Sci. Fish., p. 198, April, 1984. 
Table 1. Samples and lipid contents (wt $\%)^{*}$

\begin{tabular}{lccccc}
\hline \hline \multicolumn{1}{c}{ Sample } & TL & NL & FA & TG & FFA \\
\hline Fermented sea urchin paste & 3.1 & - & - & - & - \\
Salted sea urchin gonads A & 6.1 & - & - & - & 19.9 \\
Salted sea urchin gonads B & 8.2 & 77.4 & 74.4 & 30.2 & - \\
Raw sea urchin gonads & 5.9 & 71.9 & 64.3 & - & - \\
\hline * TL: Total lipids of a wet sample. & NL: Neutral lipids of TL. FA: Recovered fatty acids of TL. TG: Triacylglycerols of TL. \\
FFA: Free fatty aeids of TL. & &
\end{tabular}

$G$ plate of thickness $0.5 \mathrm{~mm}$ by developing with $n$-hexane/ether $(85: 15 \mathrm{v} / \mathrm{v})$, Lipids were saponified by refluxing with $1 \mathrm{~N} \mathrm{KOH-EtOH}$ for $1 \mathrm{~h}$, and the unsaponifiables were extracted with ether. Following acidification with dilute $\mathrm{HCl}$, fatty acid were recovered by ether extraction. Recovered fatty acids and FFA were converted to methyl esters by heating in a sealed tube at $100^{\circ} \mathrm{C}$ for $10 \mathrm{~min}$ with $7 \% \mathrm{BF}_{3}-\mathrm{MeOH}$. TG were converted to methyl esters by direct transesterification; heating in a sealed tube with $5 \% \mathrm{HCl}-\mathrm{MeOH}$ at $80^{\circ} \mathrm{C}$ for $3 \mathrm{~h}$ or $0.5 \mathrm{~N} \mathrm{CH} \mathrm{CH}_{3} \mathrm{ONa}-\mathrm{MeOH}$ at $60^{\circ} \mathrm{C}$ for $20 \mathrm{~min}$. The methyl esters were separated from other products by TLC under the same conditions as used in isolation of TG and FFA.

\section{Gas-Liquid Chromatography (GLC)}

Open-tubular GLC of the methyl esters was done with a Shimadzu GC 6AM and 7A instruments (Shimadzu Seisakusho Co., Kyoto) with a flame-ionization detector, on wall-coated opentubular glass column coated with SP $2300(50 \mathrm{~m} \times$ $0.3 \mathrm{~mm}$ id). The column temperature was $180^{\circ} \mathrm{C}$ and injector and detector were held at $230^{\circ} \mathrm{C}$. Peak area percentages were obtained with Shimadzu integrators C-R1A and C-R2AX. The component of each peak on the gas chromatogram was identified on the basis of comparison of the retention data with those of the reference specimen and methyl esters of sea urchin fatty acids ${ }^{12,18)}$ and algae fatty acids. ${ }^{15}$ ) The log plot procedures and systematic separation factor procedures ${ }^{15)}$ were used concurrently for the identification.

\section{Results and Discussion}

\section{Major Fatty Acid Components}

The fatty acid compositions of the lipids of samples are shown in Table 2. The major components, those percentages to the total fatty acids were above $3 \%$ in one or more samples, were $14: 0,16: 0,16: 1 \mathrm{n}-7$, iso-17:0,18:0, 18:1 n-9, $18: 1 \mathrm{n}-7,18: 4 \mathrm{n}-3,5-20: 1,20: 1 \mathrm{n}-9,5,11-20: 2$, 20:4n-6, 20:3n-3, 20:5n-3 and 22:1n-9. The total contents of the components above $3 \%$ were relatively higher, amounting to $85-90 \%$. There was no significant difference between fatty acid components of each samples.

\section{5-Olefinic Acids}

All the samples contained about $10-17 \%$ of the 5 -olefinic acids. The results were similar to those of the previous study of sea urchins. ${ }^{11-13}$ In this study, the total contents of the 5-olefinic acids were $4-7 \mathrm{mg}$ per gram of the samples. The major 5-olefinic acids of these samples were 5$20: 1,5,11-20: 2$, and 5, 13-20:2. Especially, 5-20: 1 was concentrated in polar lipids like 20:4 $\mathrm{n}-6$ and $20: 5 \mathrm{n}-3$. The 7-olefinic acid such as $7,13-22: 2$ and 7,15-22:2 were reported in the previous papers. ${ }^{11-13)}$ They were presumed to be formed by $C_{2}$ elongation of $5,11-20: 2$ and 5, 13$20: 2$. These fatty acids were also found in this study $(0.8-1.3 \%)$.

\section{Polyunsaturated Acids}

The major polyunsaturated acids of these samples were 18:4n-3, 20:4n-6, and 20:5n-3. The contents of these acids were $6-30 \%$ of total fatty acids. Especially, the salted sea urchin gonads $B$ contained $8 \%$ of $20: 4 n-6$ and $17 \%$ of $20: 5 \mathrm{n}-3$. These acids are precursors of prostaglandins, and biological activity of prostaglandins has been noticeable in biochemistry and pharmacology. The contents of 20:4 n-6 and 20: $5 \mathrm{n}-3$ were $5 \mathrm{mg}$ and $10 \mathrm{mg}$ per gram of this sample, respectively.

\section{Fatty Acids from Each Lipid}

Compositions of fatty acids from PL, NL, TG, and FFA of the salted sea urchin gonads $B$ and raw sea urchin gonads are shown in Table 2. The fatty acids from PL were generally rich in the 520: 1, 20:4 n-6, and 20:5 n-3. 20:4n-6 and 20:5 $\mathrm{n}-3$ in NL were concentrated in FFA. Fujino et $a l^{{ }^{\theta)}}$ reported that the salted sea urchin egg contained a smaller amount of TG, phosphatidyl ethanolamine, and phosphatidyl choline and a larger amount of FFA than the raw sea urchin 
Table 2. Fatty acid compositions of the lipids from the samples (wt $\%)^{*}$

\begin{tabular}{|c|c|c|c|c|c|c|c|c|c|c|c|c|c|}
\hline Fatty Acid & RRT & ECL & $\begin{array}{c}\text { Paste } \\
\text { TL }\end{array}$ & A-TL & B-TL & B-PL & B-NL & TG- & $\begin{array}{c}\text { B- } \\
\text { TGHCl }\end{array}$ & $\begin{array}{c}\text { B- } \\
\text { FFA }\end{array}$ & $\begin{array}{c}\text { Raw- } \\
\text { TL }\end{array}$ & $\begin{array}{c}\text { Raw- } \\
\text { PL }\end{array}$ & $\begin{array}{c}\text { Raw- } \\
\text { NL }\end{array}$ \\
\hline $14: 0$ & 0.263 & 14.00 & 11.44 & 8.23 & 6.86 & 5.95 & 7.57 & 8.85 & 9.24 & 6.46 & 16.45 & 11.21 & 18.77 \\
\hline iso- $15: 0$ & 0.309 & 14.47 & 0.21 & 0.30 & 0.63 & 0.41 & 0.67 & 0.85 & 0.90 & 0.62 & 1.61 & 1.56 & 1.76 \\
\hline $15: 0$ & 0.364 & 15.00 & 0.72 & 0.61 & 0.23 & 0.16 & 0.24 & 0.28 & 0.32 & 0.24 & 0.37 & 0.26 & 0.40 \\
\hline $16: 0$ & 0.525 & 16.00 & 26.39 & 27.02 & 15.31 & 17.73 & 14.32 & 19.59 & 20.23 & 14.39 & 17.62 & 14.57 & 19.37 \\
\hline $16: 1 n-7$ & 0.591 & 16.37 & 2.68 & 4.98 & 4.84 & 4.27 & 5.33 & 6.84 & 7.00 & 4.22 & 3.88 & 2.59 & 4.17 \\
\hline iso-17:0 & 0.609 & 16.46 & 2.37 & 1.83 & 1.81 & 0.50 & 2.00 & 2.27 & 2.30 & 1.90 & 4.26 & 1.85 & 4.42 \\
\hline $17: 0$ & 0.717 & 17.00 & 0.52 & 0.20 & 0.36 & 0.26 & 0.38 & 0.30 & 0.37 & 0.42 & - & - & - \\
\hline iso- $18: 0$ & 0.880 & 17.60 & 0.10 & - & 0.37 & 0.20 & 0.39 & 0.28 & 0.29 & 0.54 & 0.15 & 1 & 0.19 \\
\hline $18: 0$ & 1.000 & 18.00 & 3.50 & 4.57 & 2.48 & 3.96 & 2.06 & 1.86 & 1.99 & 2.24 & 1.40 & 2.57 & 1.33 \\
\hline $18: 15$ & 1.055 & 18.16 & 1.03 & 1.02 & 0.71 & 0.35 & 0.81 & 0.56 & 0.64 & 0.67 & 0.43 & 0.25 & 0.48 \\
\hline $18: 1 n-9$ & 1.113 & 18.33 & 2.27 & 2.64 & 1.63 & 1.48 & 1.74 & 2.54 & 2.70 & 1.37 & 3.04 & 1.49 & 3.30 \\
\hline $18: 1 \mathrm{n}-7$ & 1.143 & 18.41 & 4.84 & 3.76 & 2.62 & 1.12 & 2.76 & 2.98 & 2.97 & 2.84 & 3.86 & 1.87 & 3.92 \\
\hline $18: 1 \mathrm{n}-5$ & 1.174 & 18.49 & 0.31 & 0.30 & 0.19 & 0.08 & 0.22 & 0.15 & 0.21 & 0.22 & 0.43 & 0.22 & 0.49 \\
\hline $18: 2 n-9$ & 1.279 & 18.75 & 0.52 & 0.20 & 0.41 & 0.16 & 0.45 & 0.55 & 0.56 & 0.41 & 1.35 & 0.63 & 1.55 \\
\hline $18: 2 n-6$ & 1.314 & 18.83 & 0.72 & 1.32 & 0.96 & 0.62 & 1.07 & 1.25 & 1.16 & 1.01 & 1.24 & 0.91 & 1.27 \\
\hline $18: 3 n-6$ & 1.450 & 19.13 & 0.62 & 0.41 & 0.49 & 0.40 & 0.52 & 0.52 & 0.51 & 0.54 & 0.85 & 0.51 & 1.04 \\
\hline $18: 3 n-3$ & 1.616 & 19.46 & 0.82 & 0.81 & 1.99 & 1.12 & 2.33 & 2.29 & 1.92 & 2.37 & 1.23 & 0.67 & 1.30 \\
\hline $18: 4 n-3$ & 1.799 & 19.79 & 0.21 & 0.20 & 6.27 & 2.36 & 7.56 & 6.37 & 5.08 & 8.76 & 2.78 & 1.44 & 2.86 \\
\hline $20: 0$ & 1.928 & 20.00 & 1.03 & 1.02 & 0.66 & 0.94 & 0.55 & 0.72 & 0.78 & 0.62 & 0.57 & 0.88 & 0.48 \\
\hline $20: 15$ & 2.056 & 20.19 & 5.77 & 7.11 & 4.57 & 8.74 & 3.53 & 3.49 & 3.80 & 3.55 & 3.09 & 5.63 & 2.43 \\
\hline $20: 1 \mathrm{n}-11$ & 2.091 & 20.24 & 1.03 & 0.20 & 0.69 & 1.01 & 0.58 & 0.91 & 1.03 & 0.57 & 0.92 & 0.86 & 0.97 \\
\hline $20: 1 n-9$ & 2.150 & 20.32 & 5.15 & 4.77 & 2.75 & 3.17 & 2.63 & 3.11 & 3.19 & 2.45 & 4.67 & 3.88 & 4.85 \\
\hline $20: 1 \mathrm{n}-7$ & 2.201 & 20.39 & - & - & 0.84 & 0.62 & 0.94 & 1.02 & 1.08 & 0.96 & 1.34 & 1.04 & 1.42 \\
\hline $20: 25,11$ & 2.292 & 20.51 & 7.73 & 6.81 & 4.50 & 1.84 & 5.21 & 4.60 & 4.81 & 4.05 & 4.55 & 4.81 & 4.42 \\
\hline $20: 25,13$ & 2.320 & 20.54 & 1.75 & 1.63 & 1.33 & 0.56 & 1.40 & 1.44 & 1.56 & 1.30 & 1.81 & 1.17 & 1.96 \\
\hline
\end{tabular}


Table 2. (Continued)

\begin{tabular}{|c|c|c|c|c|c|c|c|c|c|c|c|c|c|}
\hline Fatty Acid & RRT & $\mathrm{ECL}$ & $\begin{array}{c}\text { Paste } \\
\text { TL }\end{array}$ & A-TL & B-TL & B-PL & B-NL & $\begin{array}{c}\text { B- } \\
\text { TGNa }\end{array}$ & $\begin{array}{c}\text { B- } \\
\text { TGHCl }\end{array}$ & $\begin{array}{c}\text { B- } \\
\text { FFA }\end{array}$ & $\underset{\text { TL }}{\text { Raw- }}$ & $\begin{array}{c}\text { Raw- } \\
\text { PL }\end{array}$ & $\begin{array}{c}\text { Raw- } \\
\text { NL }\end{array}$ \\
\hline $20: 2 n-6$ & 2.537 & 20.81 & 1.44 & 2.84 & 2.12 & 1.72 & 2.21 & 1.90 & 1.94 & 2.04 & 1.98 & 2.26 & 1.60 \\
\hline $20: 35,11,14$ & 2.673 & 20.96 & 0.31 & 0.41 & 0.23 & 0.12 & 0.26 & 0.20 & 0.21 & 0.30 & 0.15 & 0.18 & 0.14 \\
\hline $20: 3 n-6$ & 2.775 & 21.07 & 0.62 & 0.51 & 0.58 & 0.19 & 0.69 & 0.77 & 0.76 & 0.68 & 1.20 & 0.44 & 1.23 \\
\hline $20: 4 n-6$ & 2.982 & 21.28 & 4.74 & 4.06 & 7.63 & 9.45 & 6.24 & 4.14 & 4.01 & 7.01 & 5.92 & 15.42 & 3.57 \\
\hline $20: 3 n-3$ & 3.111 & 21.41 & 2.68 & 3.86 & 2.24 & 2.57 & 2.11 & 2.27 & 2.04 & 2.42 & 0.85 & 0.92 & 0.84 \\
\hline $20: 45,11,14,17$ & 3.273 & 21.56 & 0.11 & 0.15 & 0.26 & 0.07 & 0.27 & 0.21 & 0.18 & 0.31 & 0.08 & 0.03 & 0.09 \\
\hline $20: 4 \mathrm{n}-3$ & 3.413 & 21.68 & 0.62 & 0.41 & 2.15 & 0.51 & 2.53 & 2.26 & 1.95 & 2.79 & 1.10 & 0.47 & 1.25 \\
\hline $20: 5 \mathrm{n}-3$ & 3.691 & 21.91 & 2.27 & 1.93 & 17.01 & 18.48 & 16.31 & 9.41 & 8.63 & 18.42 & 6.14 & 12.10 & 4.11 \\
\hline $22: 1 n-9$ & 4.099 & 22.22 & 3.81 & 4.16 & 2.60 & 6.31 & 2.49 & 3.35 & 3.63 & 1.80 & 3.11 & 5.34 & 2.45 \\
\hline $22: 27,13$ & 4.384 & 22.41 & 0.21 & - & 0.23 & 0.48 & 0.19 & 0.24 & 0.24 & 0.19 & 0.29 & 0.38 & 0.29 \\
\hline $22: 27,15$ & 4.481 & 22.47 & 0.93 & 1.32 & 0.65 & 1.43 & 0.55 & 0.70 & 0.80 & 0.40 & 0.57 & 0.99 & 0.54 \\
\hline $22: 5 n-3$ & 6.935 & 23.75 & 0.21 & 0.20 & 0.34 & 0.37 & 0.33 & 0.35 & 0.34 & 0.34 & 0.12 & 0.11 & 0.13 \\
\hline $22: 6 n-3$ & 7.301 & 23.88 & 0.31 & 0.20 & 0.47 & 0.26 & 0.55 & 0.56 & 0.62 & 0.58 & 0.59 & 0.49 & 0.62 \\
\hline Total Sat. & & & 46.28 & 43.78 & 28.70 & 30.12 & 28.19 & 35.00 & 36.42 & 27.42 & 42.43 & 32.90 & 46.73 \\
\hline Total Mono. & & & 26.90 & 28.95 & 21.44 & 27.15 & 21.03 & 24.96 & 26.25 & 18.67 & 24.78 & 23.17 & 24.47 \\
\hline Total Poly. & & & 26.81 & 27.27 & 49.86 & 42.73 & 50.77 & 40.03 & 37.33 & 53.90 & 32.79 & 43.93 & 28.80 \\
\hline Total 5-Olefin & & & 16.71 & 17.12 & 11.59 & 11.69 & 11.47 & 10.50 & 11.22 & 10.19 & 10.10 & 12.08 & 9.52 \\
\hline $\mathrm{AA}+\mathrm{EPA}$ & & & 7.01 & 5.99 & 24.64 & 27.93 & 22.55 & 13.55 & 12.63 & 25.42 & 12.06 & 27.52 & 7.68 \\
\hline
\end{tabular}

* RRT: Relative retention time, ECL:l्lequivalent chain length, Paste: Fermented sea urchin paste, A: Salted sea urchin gonads A, B: Salted sea urchin gonads B, Raw: Raw sea urchin gonads, TL: Total lipids, PL: Polar lipids, NL: Neutral lipids, TG: Triacylglycerols, FFA: Free fatty acids, Na: Methylation by $\mathrm{CH}_{8} \mathrm{ONa}$, $\mathrm{HCl}$ : Methylation by HCl, Sat.: Saturated acids, Mono.: Monoenoic acids, Poly.: Polyunsaturated acids, 5-Olefin: 5-Olefinic acids, AA: 20: 4 n-6, EPA: 20: 5 n-3. 
egg. Further, they reported that unsaturated fatty acids of $\mathrm{C}_{18}-\mathrm{C}_{22}$ such as $18: 2,18: 4,20: 0$ (or $18: 3$ ), 20:1, 20:2, 20:4 (or 22:0), 20:5, and 22: 1 seemed to be liberated rather easily than the other kinds of fatty acid during curing with salt. In this study, high contents of 20:4 n-6 and 20:5 $\mathrm{n}-3$ in FFA were also caused by liberation of esterified fatty acids by activity of the enzyme.

TG were converted to methyl esters by acid catalyst and alkaline catalyst. There were no significant difference between the fatty acid compositions obtained with the two catalytic methylation methods. This result suggests that cyclic fatty acids which were unstable for acid catalyst, were not exist in the lipids of sea urchins.

\section{Comparison of Fatty Acid Compositions among Products}

The fatty acid composition of the salted sea urchin gonads A was similar to that of the fermented sea urchin paste rather than the salted sea urchin gonads B. The materials of the salted sea urchin gonads A and B were obtained from the same place (Rishiri Island), but their harvest times were different (A: November, 1979, B: July, 1982). Furthermore, fatty acid composition of the raw sea urchin gonads was different from other samples. Fujino et al $^{\text {p) }}$ reported that there was no significant difference between the total fatty acid compositions of raw and salted sea urchin eggs. Then, it is inferred that the difference between fatty acid compositions of the samples in this study are related to the fatty acid compositions of the sea urchins which are their materials.

\section{References}

1) W. V. Allen: J. Mar. Biol. Ass. U.K., 48, 521533 (1968).

2) M. Kochi: J. Shimonoseki Univ. of Fish., 25, 83153 (1976).

3) M. S. Metzman, A. Mastroianni, and J.F. Strauss: Lipids, 13, 823-824 (1978).

4) V. P. Kozhina, T. A. Terekhova, and V.I. Svetashev: Dev. Biol., 62, 512-517 (1978).

5) N. A. Romashina: Biol. Morya, No. 1, 66-68 (1983).

6) V.E. Vas'kovskii and N.A. Romanshina: Bioorg. Khim. 9, 266-269 (1983).

7) E. Y. Kostetskii and N. I. Gerasimenko: Biol. Morya, No. 1, 39-46 (1984).

8) S. V. Isay and N. G. Busarova: Comp. Biochem. Physiol., 77B, 803-810 (1984).

9) Y. Fujino, T. Negishi, and K. Umatani: Nippon Shokuhin Kogyo Gakkai-shi, 17, 343-349 (1970).

10) K. Tsuji, Y. Kawai, and S. Aso: Hokusuishi Geppo, 42, 280-292 (1985).

11) T. Takagi, C. A. Eaton, and R. G. Ackman: Can. J. Fish. Aquat. Sci., 37, 195-202 (1980).

12) Y. Itabashi and T. Takagi: Yukagaku, 29, 855865 (1980).

13) T. Takagi, M. Kaneniwa, and Y. Itabashi: Bull. Fac. Fish. Hokkaido Univ., 33, 263-269 (1982).

14) E. G. Bligh and W. J. Dyer: Can. J. Biochem. Physiol, 37, 911-917 (1959).

15) T. Takagi, M. Asahi, and Y. Itabashi: Yukagaku, 34, 1008-1012 (1985).

16) R. G. Ackman: in "Methods in Enzymology" (ed. by J. M. Lowenstein), Vol. 14, Academic Press, New York, 1969, pp. 329-381. 